\title{
Nouveauté en provenance de la Suisse Romande
}

Marianne Roth

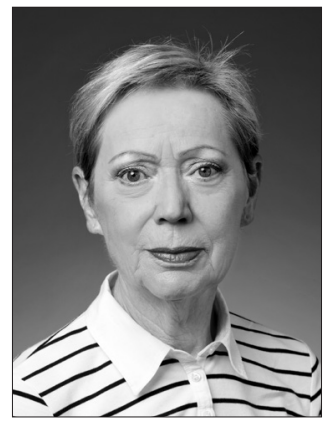

L'ASP se réjouit de pouvoir faire confirmer par l'assemblée des membres au printemps 2019 lélection de Sandra Feroleto en tant que nouveau membre du conseil d’administration. Le conseil d'administration fait usage à cette occasion de son droit de cooptation. Dans la phase actuelle, il est important que la position vacante en Suisse Romande soit rapidement occupée pour soutenir les institutions partenaires et souligner la prétention de l'association dêtre active dans toute la Suisse.

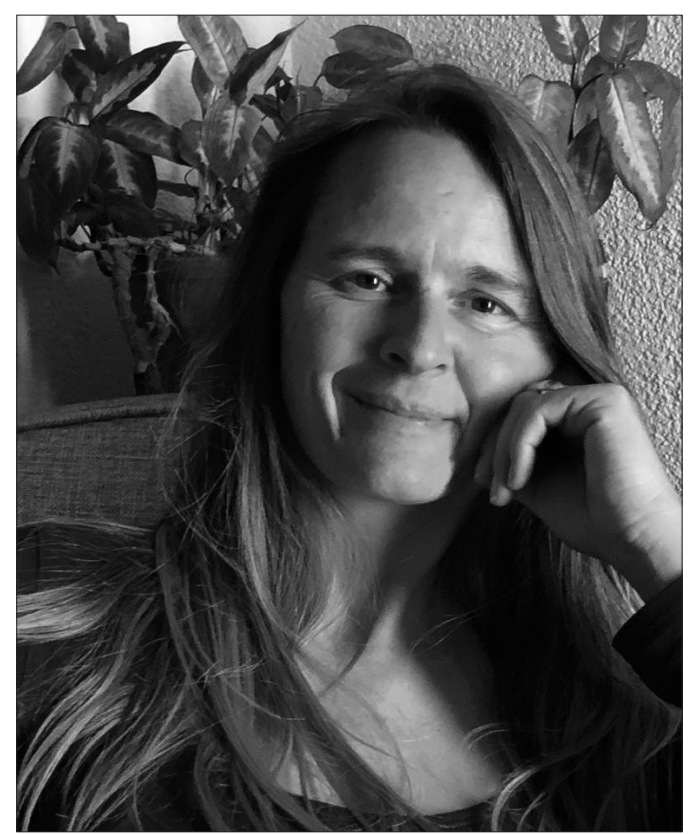

Sandra Feroleto
Le portefeuille de la formation et de la formation post-graduée de Sandra Feroleto est impressionnant et très diversifié. Elle a obtenu son diplôme de psychothérapeute à l'École Française d'Analyse Psycho-Organique (EFAPO) à Paris. Elle a auparavant obtenu un master en histoire de l'art et psychologie à l'université de Lausanne et suivi une formation à lécole supérieure de Lausanne en tant quenseignante spécialisée. Par ailleurs, elle possède un Certificate of Advanced Studies (CAS) en médiation.

Sandra Feroleto dispose d'un bon réseau, connait le "paysage de la psychothérapie » en Suisse Romande et se réjouit que l'ASP soit représentée d'une manière visible en Suisse Romande. Elle est prête à nouer des contacts avec les autorités, avec enthousiasme comme elle dit, et est convaincue que sa position sera épaulée par notre association.

En tant que membre de l'ASP, elle s'est confrontée à nos préoccupations et s'est intéressée entre autres aussi au dossier « Modèle de la prescription médicale » et au conseiller fédéral Alain Berset. Le fait que l'ASP est aussi active en matière de politique professionnelle lui plait. Comme nous, elle pense que quelque chose doit avoir lieu dans ce cas.

Nous nous réjouissons de la collaboration avec Sandra Feroleto. Elle représente d'une part un renforcement de notre conseil d'administration et offre une garantie de rapprochement avec nos membres de la Suisse Romande.

Marianne Roth est directrice générale de l'ASP. 